\title{
Pattern of cutaneous tuberculosis among children and adolescent
}

\author{
Sultana $\mathrm{A}^{1}$, Bhuiyan MSI ${ }^{1}$, Haque $\mathrm{A}^{2}$, Bashar $\mathrm{A}^{3}$, Islam MT ${ }^{4}$, Rahman $\mathrm{MM}^{5}$ \\ ${ }^{I}$ Dept. of Dermatology, Bangabandhu Sheikh Mujib Medical University (BSMMU), Dhaka, \\ ${ }^{2}$ Dept. of Public health and informatics, BSMMU, Dhaka, ${ }^{3}$ SK Hospital, Mymensingh Medical College, \\ Mymensingh, ${ }^{4}$ Dept. of Physical Medicine and Rehabilitation, BSMMU, Dhaka, \\ ${ }^{5}$ Dept. of Dermatology, National Medical College, Dhaka. \\ Email:drsaifulib@yahoo.com
}

\begin{abstract}
Cutaneous tuberculosis is one of the most subtle and difficult diagnoses for dermatologists practicing in developing countries. It has widely varied manifestations and it is important to know the spectrum of manifestations in children and adolescent. Sixty cases (age $<19$ years) of cutaneous tuberculosis were included in this one period study. The diagnosis was based on clinical examination, tuberculin reaction, histopathology, and response to antitubercular therapy. Histopahology revealed $38.3 \%$ had skin tuberculosis and $61.7 \%$ had diseases other than tuberculosis. Among 23 histopathologically proved cutaneous tuberculosis, $47.8 \%$ had scrofuloderma, $34.8 \%$ had lupus vulgaris and $17.4 \%$ had tuberculosis verrucosa cutis (TVC). Most common site for scrofuloderma lesions was neck and that for lupus vulgaris and TVC was lower limb. Cutaneous tuberculosis in children continues to be an important cause of morbidity, there is a high likelihood of internal involvement, especially in patients with scrofuloderma. A search is required for more sensitive, economic diagnostic tools.
\end{abstract}

\section{Introduction}

Tuberculosis (TB), an ancient disease has affected humankind for more than 4,000 years ${ }^{1}$ and its estimated total number of cases has reached to the highest in its history ${ }^{2}$. In Bangladesh, TB remains a major cause of morbidity and mortality ${ }^{1}$ and the burden of TB patients in Bangladesh is sixth of its world burden ${ }^{1,3,4}$. The global burden of tuberculosis among children under age 15 is $884019,11.0 \%$ of total cases of tuberculosis ${ }^{5}$.

Cutaneous TB, as like its systemic forms have a variable clinical appearance, significance and prognosis. Childhood cutaneous TB has a prevalence rate among all forms of $\mathrm{TB}$ ranges from $18.7 \%$ to $53.7 \%$ in India and other Asian countries ${ }^{6-12}$. The clinical presentation of different types of cutaneous TB varies and determined by factors such as route of infection and cellular immune status of the host ${ }^{\mathbf{1 0}}$. The current study was aimed to describe the varied clinicopathological patterns of cutaneous tuberculosis in children and adolescents.

\section{Materials and Methods}

This cross sectional observational study was conducted in all government medical college hospitals in Dhaka, Bangabandhu Sheikh Mujib Medical University (BSMMU), Bangladesh Institute of Child Health (BICH) and Institute of Diseases of Chest and Hospital (IDCH) from January to December 2010. Sixty children $(<19$ years) with tuberculosis were included after taking consent from parents or the legal guardians. A detailed history including present and past history of tuberculosis and BCG immunization status were taken and a thorough physical examination was done. Complete blood count (CBC), erythrocyte sedimentation rate (ESR), mantoux test, X-ray of chest and other regions, ultrasound of the abdomen and biopsy of the lesion were done. The mantoux test was performed using 1 tuberculin unit $(0.02 \mathrm{mg}$ of purified protein derivative) and read at 72 hours. Induration of more than $10 \mathrm{~mm}$ was taken as suggestive of infection with mycobacterium tuberculosis in non vaccinated patients and $15 \mathrm{~mm}$ and above was in vaccinated patients.

\section{Result}

In the current study, 60 children with cutaneous tuberculosis were analyzed to explore the clinicopathological spectrum of skin TB in Bangladesh. Out of them maximum $46.7 \%$ patients were within 11 to 15 years age group followed by $25 \%$ within 6-10 years, $15 \%$ more than 15 years and $13.3 \%$ up to 5 years. Mean age of the patients was $11.6 \pm 3.92$ years. 
Seventy percent were male and $30.0 \%$ female. Most $91.7 \%$ of the patients were from poor social strata and only $8.3 \%$ from middle class (Table I).

Table I: Demographic variable $(\mathrm{n}=60)$

\begin{tabular}{|c|c|c|}
\hline Variables & Frequency & Percent \\
\hline Up to 5 & 8 & 13.3 \\
\hline \multicolumn{3}{|l|}{ Age } \\
\hline $6-10$ & 15 & 25.0 \\
\hline $11-15$ & 28 & 46.7 \\
\hline$>15$ & 9 & 15.0 \\
\hline \multicolumn{3}{|c|}{ Mean \pm SD $($ range $)=11.6 \pm 3.92(4-18)$} \\
\hline \multicolumn{3}{|l|}{ Sex } \\
\hline Male & 42 & 70.0 \\
\hline Female & 18 & 30.0 \\
\hline Total & 60 & 100.0 \\
\hline \multicolumn{3}{|c|}{ Socioeconomic status } \\
\hline Poor & 55 & 91.7 \\
\hline Middle & 5 & 8.3 \\
\hline
\end{tabular}

Five percent of the children had previous history of tuberculosis, $10 \%$ had family history of tuberculosis and only one patient had radiological evidence of pulmonary tuberculosis. Seventy five percent of children had single and $25 \%$ had multiple lesion on skin. Histopahology revealed $38.3 \%$ had skin tuberculosis and $61.7 \%$ had diseases other than tuberculosis. Among 23 histopathological proved cutaneous tuberculosis, $47.8 \%$ had scrofuloderma, $34.8 \%$ had lupus vulgaris and $17.4 \%$ had TVC (Table II).

Table II: Distribution of the clinico-pathological characteristics of the patients with cutaneous tuberculosis $(n=60)$

\begin{tabular}{lll}
\hline Variables & Frequency & Percent \\
\hline Previous history of TB & 3 & \\
Present & 57 & 5.0 \\
Absent & & 95.0 \\
Family history of tuberculosis & 6 & 10.0 \\
Present & 54 & 90.0 \\
Absent & & \\
X-ray chest findings & 1 & 1.7 \\
Pulmonary TB & 59 & 98.3 \\
Normal & & \\
Number of lesion & 45 & 75.0 \\
Single & 15 & 25.0 \\
Multiple & & \\
Histopathology & 23 & 38.3 \\
Skin TB & 37 & 61.7 \\
Other than Skin TB & & \\
Clinico-pathological types(n=23) & 11 & 47.8 \\
Scrofuloderma & 8 & 34.8 \\
Lupus vulgaris & 4 & 17.4 \\
Tuberculosis Verrucosa Cutis (TVC) &
\end{tabular}

Most common site of scrofuloderma was neck (figure 1) and that for lupus vulgaris and TVC was lower (figure 2) limb. Second most common site for scrofuloderma was groin and that for lupus vulgaris was face (figure 3). Lymph node was found enlarged in $5(45.3 \%)$ cases of scrofuloderma and $1(12.5 \%)$ cases of lupus vulgaris. In TVC systemic involvement was not found. All (100\%) of lupus vulgaris and
TVC cases and $90.9 \%$ of scrofuloderma cases were found immunized with BCG. Mantoux positivity was found in $63.6 \%$ of scrofuloderma cases, $62.5 \%$ lupus vulgaris and $100 \%$ of TVC cases (Table III).

Table III: Pattern of presentation of the cutaneous tuberculosis

\begin{tabular}{llcc}
\hline Character & $\begin{array}{c}\text { Scrofuloderma } \\
(\mathrm{n}=11)\end{array}$ & $\begin{array}{c}\text { Lupus } \\
\text { vulgaris } \\
(\mathrm{n}=8)\end{array}$ & $\begin{array}{c}\text { Tuberculosis } \\
\text { Verrucosa } \\
\text { Cutis } \\
\text { (TVC) }(\mathrm{n}=4)\end{array}$ \\
\hline Most common site & Neck & Lower limb & Lower limb \\
Second most common site & Groin & Face & \\
Systemic Lymph node & $5(45.3 \%)$ & $1(12.5 \%)$ & None \\
involvement others & none & $1(12.5 \%)$ & None \\
BCG vaccination & $10(90.9 \%)$ & $8(100.0 \%)$ & $4(100.0 \%)$ \\
Mantoux positivity & $7(63.6 \%)$ & $5(62.5 \%)$ & $4(100.0 \%)$ \\
\hline
\end{tabular}

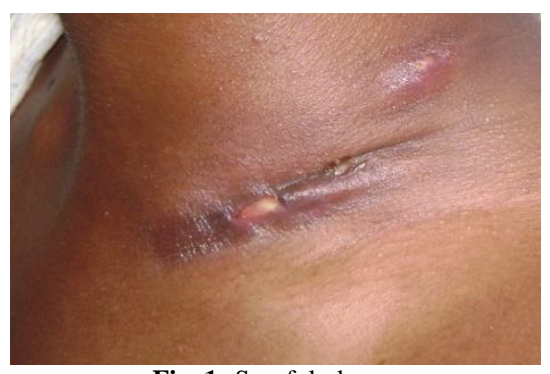

Fig. 1: Scrofuloderma

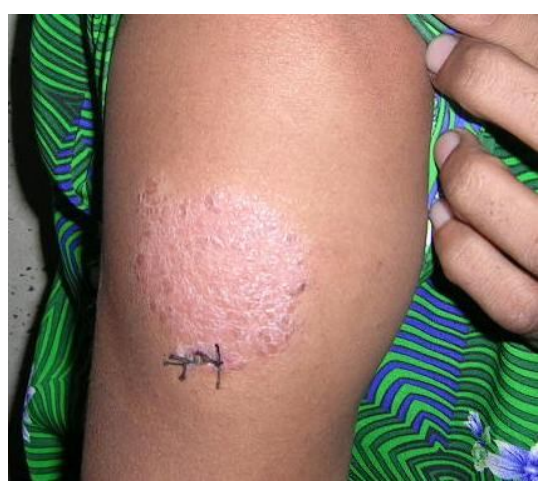

Fig. 2: Tuberculosis verrucosa cutis (TVC)

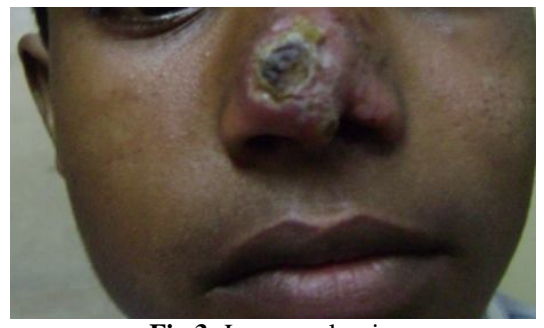

Fig.3: Lupus vulgaris.

\section{Discussion}

Tuberculosis (TB) is a major public health problem in Bangladesh. In 2008, the World Health Organization (WHO) ranked Bangladesh sixth among the world's 22 high-burden TB countries. The incidence of both pulmonary and extra pulmonary TB 
is expected to rise. The emergence of HIV virus has led to a $20 \%$ increase in incidence of extra pulmonary $\mathrm{TB}$ in the U.S ${ }^{\mathbf{1 3}}$. Although the prevalence of cutaneous TB in Bangladesh is not known, it accounts for $0.1-0.9 \%$ of the total dermatology outpatients in India ${ }^{6,14}$. Cutaneous tuberculosis represents $1.5 \%$ of all cases of extra pulmonary tuberculosis ${ }^{15}$.

The current study was conducted to see the pattern of cutaneous tuberculosis in children and adolescent in Bangladesh. Cutaneous TB affects the entire age spectrum in children ${ }^{16}$. Majority of children in the current study were from the age group of 11 to 15 years with a mean age of the patients was $11.6 \pm 3.92$ years, which is close to some previous studies (10 to 14 years group) though these can not be compared with many other studies as different studies had different age group ${ }^{6,17,18}$.

Tuberculosis in children usually contracted from infected family members, in the current study $5 \%$ of the children had previous history of tuberculosis, $10 \%$ had family history of tuberculosis and only one patient had radiological evidence of pulmonary tuberculosis. In different Indian studies an infected parent or close household member were found in $19.0 \%$ to $41.2 \%$ cases ${ }^{\mathbf{9} 10,19}$. Most $(91.7 \%)$ of the patients in the current study in agreement with previous Indian studies, ${ }^{9,10,19}$ were from poor social strata and only $8.3 \%$ from middle class. In developed countries, $10-15 \%$ of TB cases have extra-pulmonary involvement, but in patients from high-incidence countries the rate is much higher. People who are HIV positive and infected with TB develop extrapulmonary disease much more frequently, up to $50 \%$ of cases ${ }^{18}$.

Confirmatory diagnosis and exclusion other differential diagnosis of skin TB by clinical features and histopathology is really difficult, ${ }^{\mathbf{9}, 21}$. In the current study among sixty clinically diagnosed skin TB cases only $23(38.3 \%)$ was histopathologically diagnosed as skin TB. Among those Scrofuloderma was the most common pattern of skin TB in children and adolescent, which was consistant with different previous India studies, ${ }^{6,10,11,19}$. The second most common type of skin TB seen in the current study was lupus vulgaris which is considered as the most common type in adult ${ }^{6,11,16}$. Although TVC is defined as uncommon form of cutaneous tuberculosis among Indian children ${ }^{16}$, higher rate was found in Hongkong $^{22}(65.5 \%)$ and other Indian studies $\mathbf{6 , 1 0 , 1 1 , 1 9}$ and it was found in $17.4 \%$ cases of our series.
In agreement with previous studies, majority of the Scrofuloderma lesions were located on neck area $^{\mathbf{6}, 10,11,19}$. Most of the lupus vulgaris lesions were situated on lower limb which is explained by high prevalence of children with habit of out door games without clothings ${ }^{16}$ and TVC was found typically on exposed part of the body (lower limb) ${ }^{6,10,11,19}$.

Scrofuloderma commonly results from contiguous involvement of the skin overlying tuberculosis in a deeper structure, which is most commonly lymph node, bone or joint ${ }^{6,7,10,11}$. In the current study, in $45.3 \%$ of Scrofuloderma patients have enlarged lymph node and only one cases of lupus vulgaris patient had lung and lymph node involvement and none of TVC cases had systemic involvement. Some studies ${ }^{6,11,22,23}$, demonstrated that BCG immunization has some protective role against skin TB and others failed to demonstrated such association, ${ }^{9,11}$. In the current study, 90.9\% patients of Scrofuloderma, all of lupus vulgaris and tuberculosis Verrucosa cutis cases were vaccinated for BCG. The Mantoux test, a good screening test for TB infection was found to be positive in $>90.0 \%$ children with $\mathrm{TB}^{\mathbf{6 , 1 9}}$. In the current study $63.6 \%$ of Scrofuloderma, $62.5 \%$ lupus vulgaris and $100.0 \%$ of TVC patients found to be positive for Mantoux test.

Skin tuberculosis as well as other extra-pulmonary TB is an important issue in the era of HIV-AIDS. As current and newer diagnostic tools are not enough sensitive, specific or cost effective in its diagnosis, knowing its clinical pattern and presentation is important. Scrofuloderma is the most common type of skin TB in children and adolescent scrofuloderma is the most common type of skin TB in children and adolescent followed by lupus vulgaris and tuberculosis verrucosa cutis (TVC).

\section{Reference}

1. Zaman K, Hossain S, Yunus M, Arifeen SE, Mahmud A, Begum V, Islam A et al. Tuberculosis in Bangladesh: A 40-Year Review. 11 ASCON. ICDDR,B. Scientific session, 4-6 March 2007; abstract book 2007;86.

2. Stop TB. [On- line]. 24-hour World TB Day music marathon begins at midnight, 24 March, 2010; Available: http://stoptb.org/news/stories/2010/tobecontinued.asp. Accessed: March 24, 2010.

3. Prothom Alo. In collaboration with Brac January 5, 2007; page: 11 .

4. USAID Bangladesh (2009). [On- line]. Bangladesh. Available:http://www.usaid.gov/our_work/global_health/ id/tuberculosis/countrie s/asia/bangladesh.pdf. Accessed: Feb 7, 2010. 
5. Nelson LJ, Wells CD. Global epidemiology of childhood tuberculosis. Int J Tuber Lung Dis 2004; 8: 636.

6. Kumar B, Rai R, Kaur I, Sahoo B, Muralidhar S, Radotra BD. Childhood cutaneous tuberculosis: A study over 25 years from northern India. Int J Dermatol 2001;40:26-32.

7. Singh G. Lupus vulgaris in India. Indian J Dermatol Venereol Leprol 1974; 40: 257-60.

8. Umapathy KC, Begum R, Ravichandran G, Rahman F, Paramasivan $\mathrm{CN}$, Ramanathan VD. Comprehensive findings on clinical, bacteriological, histopathological and therapeutic aspects of cutaneous tuberculosis. Trop Med Int Health 2006; 11: 1521-8.

9. Ramesh V, Misra RS, Beena KR, Mukherjee A. A study of cutaneous tuberculosis in children. Pediatr Dermatol 1999; 16: 264-9.

10. Vashisht P, Sahoo B, Khurana N, Reddy BS. Cutaneous tuberculosis in children and adolescents: A clinicohistological study. J Eur Acad Dermatol Venereol 2007; 21: 40-7.

11. Singal A, Mohanty S, Gandhi V, Bhattacharya S. Cutaneous tuberculosis in paediatric age group. In Proceedings; $7^{\text {th }}$ Congress of European Society for Paediatric Dermatology; 2002. p. 33-4.

12. National Tuberculosis Control Programme, Bangladesh Report of the Fourth Joint Review 17-28 October 2007 WHO Project: BAN TUB 06.

13. Barnes PF, Bloch AB, Davidson PT, Snider DE. Tuberculosis in patients with human immunodefi $\neg$ ciency virus infection. N Engl J Med. 1991; 324: 1644-50.

14. Kumar B, Muralidhar S. Cutaneous tuberculosis: a twenty-year prospective study. Int $\mathbf{J}$ Tuberc Lung Dis 1999; 3: 494-500.
15. Gawkrodger D.J. In: Champion R.H., Burton J.L., Burns D.A., Breathnach S.M., eds. Mycobacterial infections. Textbook of Dermatology. Oxford, Blackwell Scientific Ltd. 1998: 1187-206.

16. Singal A, Sonthalia S. Cutaneous tuberculosis in children: The Indian perspective. Indian $\mathrm{J}$ Dermatol Venereol Leprol [serial online] 2010 [cited 2011 Oct 3]; 76: 494-503.

17. Global tuberculosis control: Epidemiology, strategy, financing: WHO report 2009. Geneva, World Health Organization, 2009 (WHO/HTM/TB/2009.411).

18. Kaur S, Thami GP, Kanwar AJ, Mohan H. Scrofuloderma with multiple organ involvement in a 5year-old child. Pediatr Dermatol 2001; 18: 328-31.

19. Pandhi D, Reddy BS, Chowdhary S, Khurana N. Cutaneous tuberculosis in Indian children: The importance of screening for involvement of internal organs. J Eur Acad Dermatol Venereol 2004; 18: 546-51.

20. Harahap M. Tuberculosis of the skin. Int J Dermatol $1983 ; 22: 542-545$

21. Ramesh V, Misra RS, Jain RK. Secondary tuberculosis of the skin-Clinical features and problems in laboratory diagnosis. Int J Dermatol 1987; 26: 578-581.

22. Wong KO, Lee KP, Chiu SF. Tuberculosis of the skin in Hong Kong. A review of 160 cases. Br J Dermatol 1968; 80: 424-9.

23. Zodpey SP, Shrikhande SN, Maldhure BR, Kulkarni SW. Effectiveness of Bacillus Calmette Guerin (BCG) vaccination in the prevention of tuberculosis of skin: A case control study. Indian J Dermatol 1998; 43: 4-6. 